\title{
Prevalence of Foot Deformity among Urban Young Working Women
}

\author{
YeokPin Chua ${ }^{1}$, WeiJing Tan², Aik Saw ${ }^{3}$
}

\begin{abstract}
Background: Pathological foot deformities in the adult population are more prevalent in women and many are closely related to ill-fitting footwear. To date, most literature related to footwear and foot health is based on Western society or developed nations. We conduct this study to establish the prevalence of foot deformity in young women working in an urban area.

Materials and methods: This is a cross-sectional study on young working women age between 21 years and 40 years through the convenience sampling method. Data on the foot problems were collected through a surveyor-directed questionnaire and clinical examination of the feet.

Results and discussion: A total of 400 working women with a mean age of 29.4 years were recruited into the study. More than half (65.0\%) of the women had normal body mass index (BMI). About half (52.8\%) of the women had foot deformity of different severity, but only 54 (25.6\%) of them were aware of these deformities. One hundred and six women (26.5\%) had skin hyper-callosity, $47(11.8 \%)$ had hallux valgus, and 46 (11.5\%) had lesser toe deformity. Our result showed that the prevalence of foot deformity was much higher in women wearing high-heel shoes to work which was statistically significant $(p<0.001)$. However, there was no statistically significant relationship between foot deformity with age, race, and BMI.

Conclusion: In young working women, deformity of the foot is associated with wearing high-heel footwear to work. Public awareness of the potential adverse effect of high heel shoes may help to reduce the prevalence of non-traumatic foot deformity in these women.

Keywords: Foot deformities, High-heel shoe, Young working women.

Journal of Foot and Ankle Surgery (Asia Pacific) (2021): 10.5005/jp-journals-10040-1154
\end{abstract}

\section{INTRODUCTION}

Foot deformity in the adult population is more common in women. They include mild, flexible flat foot, and splay foot which were considered physiological variations. Pathological foot deformity is relatively less common in the younger age group. Spahn et al. ${ }^{1}$ reported a $13.7 \%$ prevalence of foot deformities among adolescents in Germany. Another survey by Bogut et al. ${ }^{2}$ conducted in a sample of 426 first- to fourth-grade primary school children, indicated that the largest number of subjects had no noticeable foot deformity. On the other hand, pathological foot deformities are more common in adults and elderly populations, ${ }^{3,4}$ and they include hallux valgus, bunionette, fewer toes deformities, and metatarsalgia. Many of them were closely related to ill-fitting footwear. ${ }^{5,6}$

Most literature related to footwear and foot health is based on data from Western society and developed nations. To date, virtually no information is available pertaining to this issue in developing countries. The environment, behavioral pattern, and shoe-wearing habit varied significantly between different communities. We conduct this study to investigate the prevalence of foot deformity and associating factors among young working women in Malaysia.

\section{Materials and Methods}

This is a cross-sectional study on a group of women enrolled from outpatient clinics of the University Malaya Medical Centre. The study was approved by the ethical committee of the institution. Women were recruited through convenience sampling method. The sample population consisted of women aged between 21 years and 40 years who were working or residing in the catchment area of our tertiary referral hospital. They were mostly patients seeking treatment for injury not involving the lower limbs, accompanying
${ }^{1}$ Department of Orthopaedics (Foot and Ankle Orthopaedic Surgery), Institute of Medical Healthcare Development, Sunway University, Sunway Medical Centre, Selangor, Malaysia

${ }^{2}$ Department of Orthopaedic Surgery, KPJ Maharani Specialist Hospital, Muar, Johor, Malaysia

${ }^{3}$ Department of Trauma and Orthopaedics, National Orthopaedic Centre of Excellent for Research and Learning, University of Malaya, Kuala Lumpur, Malaysia

Corresponding Author: YeokPin Chua, Department of Orthopaedics (Foot and Ankle Orthopaedic Surgery), Institute of Medical Healthcare Development, Sunway University, Sunway Medical Centre, Selangor, Malaysia, Phone: +60193309245, e-mail: yeokpin1@yahoo.com

How to cite this article: Chua YP, Tan WJ, Saw A. Prevalence of Foot Deformity among Urban Young Working Women. J Foot Ankle Surg (Asia Pacific) 2021;8(2):76-79.

Source of support: Nil

Conflict of interest: None

person for our patients, and our hospital staffs. We excluded women with any form of congenital foot deformity, history of previous lower limb trauma which may directly or indirectly alter the anatomy or biomechanics of the foot or ankle, and those with underlying chronic medical conditions like inflammatory arthritis and diabetes mellitus.

The data were collected through an investigator-directed questionnaire and clinical examination of the foot. Information collected included demographic data, education level, occupation, body weight $(\mathrm{kg})$, and height $(\mathrm{m})$. The body mass index (BMI) was calculated and classified based on the World Health Organization 
guideline $1980^{7}$ [underweight (BMI < 18.5); ideal weight (BMI 18.5-24.9); overweight (BMI 25.0-29.9); and obese (BMI $\geq 30$ )].

For information related to footwear, we focus on shoes worn during the period of work. Is it a culture for people in this region not to wear shoes at home? The women were shown pictures of standard shoe types (high-heels, flats, sports, sandals, and boots) for them to recognize the type they most commonly used. We then created two groups of women: those wearing high heel shoes (heel elevation of $>2.5 \mathrm{~cm}$ or one inch) and those wearing other types of shoes. We subsequently asked the women about their perception of foot deformity, and whether they think their foot was deformed. One of the investigators would then examine the foot to identify deformities including hallux valgus, fewer toes deformities (i.e., hammer toe, clawed toe), bunionete, prominent first metatarsal head, skin hyper-callosity and other type of deformities.

Data tabulation and processing were performed using Statistical Package for the Social Sciences version 16.0 (SPSS, Chicago, IL, USA). Following descriptive analysis of data, we calculated the prevalence of specific conditions using a $\mathrm{Chi}$-square test with an odds ratio and $95 \%$ confidence intervals. The difference between comfort and pain scores was tested using independent samples $t$-tests.

\section{Results}

Over the study period, we approached 432 women, and 400 agreed to participate in the study (rejection rate of $7.4 \%$ ). The average age of the women was 29 years (mean $29.4 \pm 5.20$ ). Ethnic distribution of the subjects were 208 (52.0\%) Malays, 119 (29.7\%) Chinese, 67 (16.8\%) Indians, and 6 (1.5\%) from other races (Table 1). Looking at the education background, 211 women (52.8\%) had tertiary education, 183 (45.8\%) had secondary education, and 6 (1.5\%) had only primary education. More than $60 \%$ of them were professionals or administrative staff. More than half of the women (260; 65.0\%) had normal BMI. There were 54 (13.5\%) women who were overweight and 24 (6.0\%) who were obese. We subsequently divide the footwear into high-heels and non-high-heels for further analysis.

Our study showed that more than half of the women used highheel shoes to work ( 213 out of 400 women; $53.2 \%$ ), followed by a flat shoe (112 subjects; $28.0 \%$ ), sandals (39 subjects; $9.8 \%$ ), sports shoe (25 subjects; $6.2 \%$ ), boots (8 subjects; $2.0 \%$ ), and other shoe types (3 subjects; $0.8 \%$ ) (Table 2). Based on physical examination findings, 211 (52.8\%) women have foot deformities of different severity. Interestingly, only 54 of them (25.6\%) were aware of these deformities. Skin hyper-callosity (corns) was the commonest foot deformity (106 women, $26.5 \%)$, followed by less toe deformity (46 women, $11.5 \%)$, hallux valgus (47 women, $11.8 \%$ ), prominent metatarsal head, and bunionette (Table 3). Forty women have more than one type of foot deformity present.

Our study showed that women wearing high-heel shoes to work were associated with a higher prevalence of foot deformity (69.5\%) compared to those wearing other types of shoes to work (33.7\%), and the difference was highly significant $(p<0.001)$ (Table 4).

Table 1: Demographic characteristic of the subjects and their relation with foot deformity

\begin{tabular}{|c|c|c|}
\hline Categories & $\begin{array}{l}\text { Number of subjects with foot } \\
\text { deformity (\%) }\end{array}$ & $\begin{array}{l}\text { Number of subjects with no } \\
\text { foot deformity (\%) }\end{array}$ \\
\hline \multicolumn{3}{|c|}{${ }^{\mathrm{a} A g e}$ group by year ( $n=$ number of subjects) } \\
\hline $21-25(n=111 ; 27.8 \%)$ & $53(47.7)$ & $58(52.3)$ \\
\hline $26-30(n=127 ; 31.8 \%)$ & $67(52.8)$ & $60(47.2)$ \\
\hline $31-35(n=97 ; 24.3 \%)$ & $50(51.5)$ & $47(48.5)$ \\
\hline $36-40(n=65 ; 16.1 \%)$ & $41(63.1)$ & $24(36.9)$ \\
\hline \multicolumn{3}{|l|}{${ }^{\mathrm{b}}$ Major races ( $n=$ number of subjects) } \\
\hline Malay $(n=208)$ & $110(52.9)$ & $98(47.1)$ \\
\hline Chinese $(n=119)$ & $63(52.9)$ & $56(47.1)$ \\
\hline Indian $(n=67)$ & $34(50.7)$ & $33(49.3)$ \\
\hline \multicolumn{3}{|c|}{${ }^{\mathrm{C} C}$ ategory (BMI range) ( $n=$ number of subjects) } \\
\hline Underweight (BMI < 18.5), $n=62$ & $33(53.2)$ & $29(46.8)$ \\
\hline Optimal (BMI 18.5-24.9), $n=260$ & $141(54.2)$ & $119(45.8)$ \\
\hline Overweight (BMI 25-29.9), $n=54$ & $25(46.3)$ & $29(53.7)$ \\
\hline Obese $(\mathrm{BMI}>30), n=24$ & $12(50.0)$ & $12(50.0)$ \\
\hline
\end{tabular}

${ }^{\mathrm{a}} \mathrm{X}^{2}=3.952$ with $3^{\circ}$ of freedom; $p=0.359$

${ }^{\mathrm{b}} \mathrm{X}^{2}=0.104$ with $2^{\circ}$ of freedom; $p=0.949$

${ }^{c} X^{2}=1.210$ with $3^{\circ}$ of freedom; $p=1.000$

Table 2: Prevalence of various foot deformities based on type of footwear for work

\begin{tabular}{|c|c|c|c|c|c|c|}
\hline $\begin{array}{l}\text { Footwear type } \\
\text { (subjects number) }\end{array}$ & $\begin{array}{l}\text { Subjects with foot } \\
\text { deformity (\%) }\end{array}$ & Skin hyper-callosity & $\begin{array}{l}\text { Lesser toe } \\
\text { deformity }\end{array}$ & Hallux valgus & $\begin{array}{l}\text { Prominent first } \\
\text { metatarsal head }\end{array}$ & Bunionette \\
\hline High-heel (213) & $148(69.5)$ & 69 & 34 & 35 & 21 & 14 \\
\hline Flat (112) & $40(35.7)$ & 25 & 8 & 6 & 9 & 2 \\
\hline Sandal (39) & $14(35.9)$ & 6 & 3 & 3 & 3 & 1 \\
\hline Sports (25) & $6(24.0)$ & 4 & 1 & 1 & 0 & 0 \\
\hline Boot (8) & $2(25.0)$ & 1 & 0 & 1 & 0 & 0 \\
\hline Others (3) & $1(33.3)$ & 1 & 0 & 1 & 0 & 0 \\
\hline
\end{tabular}


Table 3: Frequency and prevalence of each kind of foot deformity

Prevalence (\%) in the

\begin{tabular}{lll} 
Type of foot deformity & $\begin{array}{l}\text { Number of subjects } \\
\text { affected }\end{array}$ & $\begin{array}{l}\text { Phole subject popula- } \\
\text { tion }\end{array}$ \\
\hline Skin hyper-callosity & 106 & 26.5 \\
Lesser toe deformity & 46 & 11.5 \\
Hallux valgus & 47 & 11.8 \\
Prominent metatar- & 33 & 8.3 \\
sal head & & \\
Bunionette & 17 & 4.3 \\
\hline
\end{tabular}

Table 4: Prevalence of foot deformity in high-heels and non-high-heels wearers

\begin{tabular}{lll}
\hline & $\begin{array}{l}\text { Number of } \\
\text { subjects with foot } \\
\text { deformity (\%) }\end{array}$ & $\begin{array}{l}\text { Number of } \\
\text { subjects without } \\
\text { foot deformity (\%) }\end{array}$ \\
\hline High heels $(n=213)$ & $148(69.5)$ & $65(30.5)$ \\
Non-high heels $(n=187)$ & $63(33.7)$ & $124(66.3)$ \\
\hline$x^{2}=49.76 ; p<0.001 ; 0$ )
\end{tabular}

$\mathrm{X}^{2}=49.76 ; p<0.001$; odds ratio $=4.482(95 \% \mathrm{Cl} 2.942-6.826)$

However, there was no statistically significant difference between the presence of foot deformity with age, race, and BMI (Table 1).

\section{Discussion}

The racial distribution of the women (52.0\% Malay, $29.7 \%$ Chinese, $16.8 \%$ Indian, and $1.5 \%$ of other races) was close to the finding of the National Population Census Year 2000 for female aged 21-40 in Kuala Lumpur and Selangor (52.5\% of Malay, 31.6\% of Chinese, $13.2 \%$ of Indian, and $2.7 \%$ of other races). ${ }^{8}$ All the women have some form of education, and more than half (60\%) were in the "whitecollar" category, reflecting the urban pattern of occupation. Analysis based on BMI also showed that majority (65.0\%) of subjects fall into the optimal category (BMI between 18.5 and 24.9). Henceforth, this particular group of women was expected to be healthy, welleducated and financially independent. They were assumed to have relatively healthy feet and were aware of potential harmful effect of high-fashion but ill-fitting footwear which dominated the market.

Of the 400 women, 211 (52.8\%) were noted to have some form of foot deformity clinically, but only 54 (25.6\%) were aware of these deformities. The apparent low self-awareness of foot deformity was consistent with other studies where the diagnosed conditions were found to be greater than the self-reported ones. ${ }^{9-11}$ Skin hypercallosity which affected $26.5 \%$ of women was the commonest type of deformity, and they were mainly found on the dorsal aspect of the toes. Other deformities noted were hallux valgus, fewer toe deformities (clawed and hammer toes), prominent first metatarsal head, and bunionette, with their prevalence rate of 11.8, 11.5, 8.3, and $4.3 \%$ respectively. We were not able to find any information on prevalence of foot deformities in young working women in English medical literature. The American Orthopaedic Foot and Ankle Society Women's Shoe Survey reported a much higher prevalence of foot deformities but the study involved women of a wider age range (20-60 years). They reported that $71 \%$ of the women surveyed had hallux valgus, 50\% had hammer toes, $18 \%$ had bunionette, and $13 \%$ had prominent metatarsal head..$^{12}$ With increasing age, the prevalence and the severity of foot deformity were expected to increase. ${ }^{13}$
Our study showed that women wearing high-heel shoes to work were associated with a significantly higher prevalence of developing foot deformity $[p<0.001$; odds ratio $=4.482(95 \% \mathrm{Cl} 2.942-6.826)]$ (Table 4). We noted that a high proportion of skin hyper-callosities developed at the dorsal aspect of the toes. This was thought to be a result of increased friction between dorsum of toes with the shoe when the toes were in curled up position. ${ }^{14}$ This will be aggravated by wearing of high heel shoes because the toes would be forced into the confined area of the toe box. ${ }^{6}$ Other deformities affecting the forefoot have also been associated with ill-fitting footwear. ${ }^{5}$ It has been reported that wearing footwear substantially narrower than the foot was associated with corns on the toes, hallux valgus deformity and foot pain; wearing shoes shorter than the foot was associated with fewer toes deformity; and wearing shoes with heel elevation $>25 \mathrm{~mm}$ (one inch) was associated with hallux valgus and plantar calluses. ${ }^{6}$

Subcategories of age (5-year interval), race, and BMI were found to have no significant association with the prevalence of foot deformity. Subjects of this survey were from a young age group and the difference of prevalence due to age was not anticipated. The racial factor was not expected to be relevant in the occurrence of foot deformity as there was no major difference in the footwear trend among the races.

The design of this study (a population survey) does not allow for a temporal relationship between footwear and foot problems to be established. This limitation is of particular importance in forefoot deformities, such as hallux valgus which may take many years to develop. Thus, the cause-and-effect relationship between footwear type and foot problem could not be established. Some characteristics of footwear such as toe box shape and its dimension in relation to forefoot width, which is associated with forefoot deformity, were not included in this study. ${ }^{6,12}$ The type of toe box varies between the type of footwear and even among footwear of the same type. A larger sample population will allow us to perform a more detailed comparison between the different nature of work like the need for prolonged standing or walking.

\section{Conclusion}

The prevalence of various foot deformities among young working women in our urban society was $52.8 \%$, and only a quarter of them were aware of these deformities. The presence of foot deformities was also noted to be associated with wearing of high heel footwear to work. Increasing public awareness on the prevalence of foot deformities its association with ill high-heel footwear may help young working women in our urban society to modify their footwear habits and potentially reduce the rate of severe foot problems in the future.

\section{References}

1. Spahn G, Schiele R, Hell AK, et al. The prevalence of pain and deformities in the feet of adolescents. Results of a cross-sectional study. Z Orthop Ihre Grenzgerb 2004;142(4):389-396. DOI: 10.1055/s2004-822844.

2. Bogut I, Popovic Z, Tomac Z, et al. Prevalence of foot deformities in young schoolchildren in Slovonia. Acta Clin Croat 2019;58(2):288-294.

3. Benvenuti F, Ferrucci L, Guralnik JM, et al. Foot pain and disability in older persons: an epidemiologic survey. J Am Geriatr Soc 1995;43(5):479-484. DOI: 10.1111/j.1532-5415.1995.tb06092.x. 
4. Dunn JE, Link CL, Felson DT, et al. Prevalence of foot and ankle conditions in a multiethnic community sample of old adults. Am J Epidemiol 2004;159(5):491-498. DOI: 10.1093/aje/ kwh071.

5. Frey C, Thompson F, Smith J. Update on women's footwear. Foot Ankle 1995;16(6):328-331. DOI: 10.1177/107110079501600603.

6. Menz HB, Morris ME. Footwear characteristics and foot problems in older people. Gerontology 2005;51(5):346-351. DOI: $10.1159 / 000086373$.

7. WHO, 1980 . Obesity: preventing and managing the global epidemic. Geneva: World Health Organization; 1997, June 3-5.

8. Department of Statistics Malaysia. Population and Housing Census of Malaysia 2010. National Population Demographics Census Year 2000 for female aged 21 to 40 in Kuala Lumpur and Selangor. Available at: www.statistics.gov.my/mycensus 2010. Accessed July 23, 2011.
9. Cartwright A, Henderson G. More trouble with feet: a survey of the foot problems and chiropody needs of the elderly. London: HMSO; 1986.

10. Clarke M. Trouble with feet. Occasional papers on social administration No, 29. London: Bell; 1969.

11. Garrow AP, Silman AJ, Macfarlane GJ. The cheshire foot pain and disability survey: a population survey assessing prevalence and associations. Pain 2004;110(1-2):378-384. DOI: 10.1016/j. pain.2004.04.019.

12. Frey C, Thompson F, Smith J, et al. American orthopaedic foot and ankle society women's shoe survey. Foot Ankle 1993;14(2):78-81. DOI: 10.1177/107110079301400204.

13. Coughlin MJ, Thomson FM. The high price of high-fashion footwear. Instr Course Lect 1995;44:418-422.

14. Singh D, Bentley G, Trevino S. Callosities, corns and calluses. Postgrad Med 1984;75:191-198. 